Cite as:

Alburez-Gutierrez, D., Kolk, M. and Zagheni E. (2021). Women's experience of child death: A global demographic perspective. Demography. DOI: 10.1215/00703370-9420770.

\title{
Women's Experience of Child Death Over the Life Course: A Global Demographic Perspective
}

\author{
Diego Alburez-Gutierrez ${ }^{1 *}$, Martin Kolk ${ }^{2}$, Emilio Zagheni $^{1}$ \\ ${ }^{1}$ Laboratory of Digital and Computational Demography, Max Planck Institute for Demographic Research \\ ${ }^{2}$ Stockholm University Demography Unit, Stockholm University \\ *To whom correspondence should be addressed: alburezgutierrez@ demogr.mpg.de
}

Updated: May 25, 2021

\begin{abstract}
The death of a child affects the well-being of parents and families worldwide, but little is known about the scale of this phenomenon. Using a novel methodology from formal demography applied to data from the 2019 Revision of the United Nations World Population Prospects, we provide the first global overview of parental bereavement, its magnitude, prevalence, and distribution over age for the 1950-2000 annual birth cohorts of women. We project that the global burden of parental bereavement will be 1.6 times lower for women born in 2000 than for women born in 1955. Accounting for compositional effects, we anticipate the largest improvements in regions of the Global South, where offspring mortality continues to be a common life event. This study quantifies an unprecedented shift in the timing of parental bereavement from reproductive to retirement ages. Women in the 1985 cohort and subsequent cohorts will be more likely to lose an adult child after age 65 than to lose a young child before age 50, reversing a long-standing global trend. "Child death" will increasingly come to mean the death of adult offspring. We project persisting regional inequalities in offspring mortality and in the availability of children in later life, a particular concern for parents dependent on support from their children after retirement. Nevertheless, our analyses suggest a progressive narrowing of the historical gap between the Global North and South in the near future. These developments have profound implications for demographic theory and highlight the need for policies to support bereaved older parents.
\end{abstract}

Keywords Mortality, Population change, Kinship, Formal demography, Global health 


\section{Introduction}

The adage that "no parent should have to bury a child" reflects a long-standing societal aspiration that deaths over the life course should follow an orderly sequence, with the deaths of earlier generations preceding those of later generations. In reality, however, the mortality rates of young children have been extremely high for most of human history and continue to be high in many contemporary populations (Volk and Atkinson 2013). High child mortality levels are a key feature of a long-standing demographic regime that has been changing rapidly as average levels of mortality and fertility decline around the world.

The death of a child affects parental well-being (Hendrickson 2009; Lee et al. 2014) and has been linked to higher mortality for parents, particularly for mothers (Li et al. 2003; Rostila et al. 2012). Offspring mortality also affects the availability of social, emotional, and financial support in the family (Verdery and Margolis 2017; Umberson et al. 2017), which is especially detrimental for parents who planned their lives with the expectation that their children would survive to provide them with social support at old ages (Lee 2013). Shifts in offspring mortality have important implications for inequalities in access to care and family support in the context of an aging global population (Lee 2011). Parents in low-income countries, who are expected to experience a radical demographic transformation in the coming years but often lack access to effective pension systems and welfare regimes, are likely to be the most vulnerable.

The demographic transition, defined as a historical regularity (Caldwell 1978) and a framework for conceptualizing global population change (Lesthaeghe 2014; Reher 2019), is often represented as a movement from demographic disorder to order. An influential view 
portrays it as a transition toward a "natural chronological hierarchy" of death (Livi Bacci 1997). However, the demographic transition's effect on the experience of child death over a woman's life course is not self-evident, given that improvements in longevity, declines in fertility, and the postponement of fertility affect kinship dynamics in complex ways. On the one hand, increases in the mean ages at childbirth and decreases in total fertility may reduce women's exposure to the death of young children (Uhlenberg 1980, 1996). On the other hand, global population aging seems inevitable over the long term (Lee 2011) and with it an aging of generational relationships (Murphy 2011) in which life events such as the death of a child are postponed to older ages.

In this article, we explore the effects of past and future global demographic changes on the experience of child death from the perspective of the women living through them in different regions of the world. We ask how sustained fertility decline and rising life expectancy driven by radical reductions in young child mortality affect the experience of offspring mortality over the life course. To answer this question, we propose a new approach based on formal demographic relationships. We refer to this technique as the "kin-cohort method" to distinguish it from survey-based approaches that rely on period data and to emphasize the generalizability of the approach, which can be extended to other types of kin beyond children. We estimate and predict offspring mortality over the entire life course by applying our method to data from the 2019 Revision of the United Nations World Population Prospects (UN WPP) (UNDESA 2019). Our analysis centers on the frequency and timing of the experience of child death to determine how common the experience of losing a child will become and at what stage of the life course it is most likely to occur for women born between 1950 and 2000. The calculations refer to male and female children of women.

We focus on women's experiences because child death is more detrimental for mothers 
than for fathers (Hendrickson 2009; Li et al. 2003) and because high-quality international data on male fertility are lacking (Schoumaker 2019). We analyze a total of 150 years of demographic data for the 201 countries and territories included in the UN WPP with the aim of providing the first global overview of the phenomenon while emphasizing regional differences related to the prevailing demographic regimes. The world population is highly diverse, and our data include low- and high-income countries. Indeed, over the extensive period we consider, some of these countries transitioned from lower to higher income levels.

Our study makes three important contributions. Empirically, it is the first study to present a complete life course overview of women's experiences of child death by moving beyond conventional measures of infant and child mortality that consider only the deaths of young children during a woman's reproductive ages. We also consider the deaths of offspring who are infants, children, teenagers, or adults that are experienced by women between the ages of 15 and 100. Thus, we acknowledge the reality that the death of a woman's offspring can occur at any stage of her life course, not just when she and her offspring are young. Methodologically, the proposed kin-cohort method overcomes the data constraints that affect survey-based studies, which are limited to women of reproductive age by design. We combine 70 years of historical demographic rates and 80 years of projected data from the UN WPP to estimate levels of offspring mortality for women who are, for example, 80 or 90 years old. Furthermore, we make realistic projections about the future burden of offspring mortality for young women who are alive today and have not yet experienced parental bereavement. Traditional approaches would require us to wait for more than 60 years to determine whether a newly born child will outlive her mother, but our approach allows us to project the proportion of children who will outlive their mothers even for women currently entering their reproductive years. Third, this is the first 
study to provide reliable estimates of the present and future burden of child death for every country in the world. Although the negative consequences of parental bereavement are known, we are aware of only one study that quantified the phenomenon for some countries in subSaharan Africa, and it was limited to women of reproductive age (Smith-Greenaway and Trinitapoli 2020). Thus, researchers and policy-makers are in the dark regarding the current and future dimensions of this problem in most other countries.

\section{Life Course Effects of Parental Bereavement}

Extensive research has documented the continuous progress that has been made in reducing young-age mortality around the world, with a particular focus on under- 1 and under-5 mortality, both historically (Volk and Atkinson 2013) and in contemporary populations (Hug et al. 2018; You et al. 2015). However, despite the long-standing interest in cumulative measures of mortality (Wilmoth 2009), this period view of mortality has largely ignored the experience of offspring death over the complete life course of a parent. This research gap is partly due to a lack of data. Period studies of child mortality often rely on population surveys, which are generally conducted in selected countries at irregular intervals and do not provide a life course perspective on offspring mortality. For example, the birth histories from the Demographic and Health Surveys (DHS) record child deaths only during a woman's reproductive lifespan (age 15-49) while leaving out the deaths of any offspring older than age 34 (given the few births to girls under age 15). Life course estimates of offspring mortality could be derived from population registers, but such estimates have important limitations as well. First, these estimates are available for only a handful of countries and are hardly representative of the world's population. Second, these estimates are constrained by time, given that cohort data are reconstructed retrospectively; the cumulative number of offspring deaths at age 50, for example, is known only 
for parents born half a century ago.

Parent-centered measures of mortality matter because parental bereavement affects parents' psychological, physical, and material well-being. For parents, the death of a young child is associated with an increased risk of mortality (Espinosa and Evans 2013; Li et al. 2003; Rostila et al. 2012), depressive symptoms (Lee et al. 2014; Wijngaards-de Meij et al. 2005), lower self-rated health (Hendrickson 2009), and lower overall quality of life (Rogers et al. 2008; Song et al. 2010). This traumatic event can influence health-related behaviors, such as diet, smoking, or alcohol consumption (Hendrickson 2009). It can also affect couple dynamics between parents (Albuquerque et al. 2016) and increase the risk of intimate partner violence (Weitzman and Smith-Greenaway 2020). Parental bereavement generally impacts mothers more than fathers, perhaps because of gendered coping mechanisms or because mothers develop stronger emotional ties with their children (Lee et al. 2014; Li et al. 2003; Rostila et al. 2012; Wijngaards-de Meij et al. 2005). The loss of a child also has a demographic life course component. Women are more likely than men to overlap with their children's lives for a longer period, given women's younger ages at the birth of their children and greater longevity. As a result, women are also more likely to rely on children in older adulthood. For the same demographic reasons, women have, on average, longer periods of grandparenthood than men, potentially explaining the positive effect of maternal grandmothers on grandchild survival (Margolis and Verdery 2019). It is still unclear how family size and the sex of the deceased child affect parental bereavement (Meert et al. 2010), but some studies have found stronger effects following the death of an only child (Espinosa and Evans 2013; Li et al. 2003). The few studies on the effects of adult offspring mortality on mothers have also shown that older mothers who lose a child have increased mortality risks (Rostila et al. 2012) and depressive symptoms, as well 
as lower self-rated health (Lee et al. 2014). Moreover, evidence exists that the death of an adult child can interrupt the transfer of essential emotional and instrumental support to older parents (Hendrickson 2009; Lee and Mason, 2011; Seltzer and Bianchi 2013).

\section{Demographic Forces Affecting Child Death}

The demographic transition theory predicts that sustained declines in mortality are followed by reductions in fertility. The transition from high to low levels of fertility and mortality is expected to produce convergence to an older population and a more stable demographic regime (Lesthaeghe 2014; Reher 2019). This transition is not necessarily smooth: local idiosyncrasies and disruptive events, such as wars and epidemics, can affect demographic rates in unexpected ways. The HIV/AIDS epidemic in sub-Saharan Africa, for example, brought life expectancy improvements in these populations to a halt and increased people's exposure to kin death (Zagheni 2011). The demographic stability projected for high-income regions such as Europe, which underwent the transition decades or centuries ago, is a reminder of the dramatic demographic disparities around the world. We expect future changes in mortality and fertility to affect the experience of child death over a woman's life course.

The last 50 years have seen considerable improvements in mortality. Global period under-5 mortality rates fell from 213 per 1,000 live births in 1950-1954 to 46 in 2010-2015. The UN Sustainable Development Goals call for a reduction of this rate to 25 by 2030 . At the same time, period life expectancy has been increasing at a constant rate of around 2.5 years per decade worldwide, excluding large demographic shocks, such as the recent HIV/AIDS epidemic (Zagheni 2011) and the Covid-19 pandemic (Goldstein and Lee 2020). This trend is one of the most robust regularities in contemporary population dynamics (Vaupel 2010). Additional gains in life expectancy are anticipated in low-income countries, where mortality is still concentrated 
at young ages. In high-income countries, slow but sustained increases in life expectancy have reenergized the debate about whether we will approach an inflection point for trends in human lifespan (Oeppen 2002).

Lower mortality rates can increase or decrease the frequency of women's experiences of child death in a given population. When women's life expectancy is higher, mothers' exposure to the risk of experiencing a child's death may increase as the overlap between a mother's life and her children's lives expands. Lower infant, child, and young adult mortality reduce a mother's risk of experiencing a child's death during her reproductive years, when her children are young, at the expense of potentially postponing the experience of child death to older ages. As a population undergoes the demographic transition, the effect of improved survival on child death also depends on changes in the distribution of fertility over age.

Post-transition populations are characterized by lower and later fertility. The global period total fertility rate (TFR) is projected to fall from 4.97 in 1950-1954 to 1.94 by $2095-$ 2100, just below replacement level. Nearly one-half of the world population currently lives in a region with below-replacement period fertility, and this share is projected to increase (Lee 2011; Reher 2019). The largest fertility declines are expected in the Global South, where fertility is still high. Important changes are also expected in the timing of fertility, which is another key component of the demographic transition theory. The mean age at childbirth in Europe and North America is, on average, predicted to increase steadily over the projection horizon, reflecting a historical tendency for women in high-income and low-fertility countries to postpone the start of childbearing. Mean age at childbearing in sub-Saharan Africa, the world's most impoverished region, is projected to remain virtually unchanged over the same period. Changes in the age at first birth and last birth are particularly relevant to the experience of maternal bereavement, but 
these measures have not been well documented for all countries covered in this study (Reher 2019).

Foundational demographic work has already noted the expected effect of demographic change on the lived experience of child death (Uhlenberg 1980,1996). Reductions in fertility decrease the risk of offspring mortality because parents have, on average, fewer offspring to lose than parents of previous cohorts. Similarly, postponement of fertility both reduces the likelihood of experiencing child death and potentially delays the timing of child death. Levels of childlessness, resulting from nonfertility or child loss, also matter because only mothers are at risk of losing a child. Women in low-fertility settings are more likely to become childless due to child death, with all else held constant.

\section{Methodology}

We introduce the kin-cohort method, an extension of a set of classic demographic methods known as the Goodman, Keyfitz, and Pullum kinship equations (GKP equations) (Goodman et al. 1974; Keyfitz and Caswell 2005) to analyze changes in offspring mortality among women using country-level demographic rates. Our key equation states that the number of children ever born to a woman aged $a$ born in cohort $c$ standing before us will be equal to the number of children who are currently alive plus the children who died before the woman reached age $a$ :

$$
\underbrace{C D(a, c, n)}_{\text {Child deaths }}=\underbrace{\sum_{x=15}^{x=a} F_{x}(c, n)}_{\text {Children born }}-\underbrace{\sum_{x=15}^{x=a} F_{x}(c, n) l_{a-x}(c+x, n)}_{\text {Children surviving or } C S(a, c, n)}
$$

where ${ }_{1} F_{x}(c, n)$ represents single-year age-specific fertility rates for cohort $c$ and country $n$ at age $x$. The lower age boundary in this and all models is 15 , representing the start of a woman's reproductive life. The term $l_{a-x}(c+x, n)$ represents the survival probability until age $(a-x)$ for the cohort born in year $(c+x)$ in country $n$; it is the probability that the children of a woman who gave birth at age $x$ will survive until the woman potentially reaches age $a$. The terms $(a-x)$ and 
$(c+x, n)$ allow us to replace the assumption of demographic stability present in the original formulation of the GKP equations with empirical rates that vary over time. We refer to the left side of Eq. (1) as child death, which represents the cumulative number of offspring deaths conditional on the woman's survival to age $a$ for an average woman exposed to the age-specific fertility rates of her country and cohort of birth. We refer to the rightmost term of the equation as child survival, the number of children of a woman aged $a$ who are currently alive.

Our proposed method builds on the GKP equations in two important ways. First, unlike the original GKP equations, our method does not assume stable rates, making it applicable to nonstable populations with changing demographic rates. The kin-cohort method draws on the appropriate cohort-age combinations to reconstruct the particular demographic regime under which the lives of a hypothetical woman and her children elapsed. Second, the kin-cohort method can be used to estimate maternal bereavement, whereas the GKP equations were intended to capture only offspring survival.

We measure cohort changes in the lived experience of child death using data for the entire world population-201 countries and territories - from the 2019 Revision of the UN World Population Prospects (UN WPP). Historical demographic rates (1950-2019) come from harmonized primary sources (e.g., censuses, surveys, and vital registration statistics). The UN WPP also provides deterministic cohort-component projections for the 2020-2100 horizon. Projections are reported in three scenarios that vary in their model assumptions. We use the "medium variant" scenario because it is usually considered the most plausible (Lee 2011), but we find that our main findings are consistent with alternative specifications of future mortality and fertility trajectories (see the Sensitivity Analysis section). Our method requires single-age and single-year cohort demographic rates, which we approximate by taking the values along the 
diagonal of the UN WPP 2019 period rates. We expand the UN abridged life tables by interpolating single-age values of the ${ }_{n} m_{x}$ column, modeling values for the very young and very old ages separately (Preston et al. 2001). Our analysis uses estimated (i.e., not model) life tables. Applying this methodology, we approximate rates for 10,050 distinct cohorts of women, which allows us to consider offspring deaths during the entire life course (i.e., ages 15-100) of women born between 1950 and 2000; the 2000 cohort is the last one for which we can approximate cohort rates up to age 100. Population-level measures are weighted by the sizes of female birth cohorts, which we estimate from the reported numbers of annual births and the sex ratios at birth for each country. The kin-cohort method is more parsimonious and less computationally intensive than the demographic microsimulations used in previous studies of kinship availability, none of which focused on parental bereavement (Murphy 2011; Verdery and Margolis 2017; Zagheni 2011).

We present our results in the next section by comparing estimates for two birth cohorts of women. The first is a cohort of women born in 1955, who completed their reproductive lives in 2005, which means that the estimates for this cohort are less sensitive to the assumption of convergence to replacement fertility that underlies the UN WPP demographic projections (Lee 2011). This cohort selection is important because estimates of offspring mortality are particularly sensitive to changes in fertility. Crucially, at the time of this writing, the women in this cohort are 65 years old, which we take to be the age of retirement from formal employment. The second cohort comprises women born in 2000. This is the most recent cohort for which we can obtain lifetime estimates of offspring mortality from the UN WPP demographic projections using the kin-cohort method. These women are at the start of their reproductive lives and will soon make decisions about their own fertility. We highlight these two cohorts based on the assumption that 
offspring loss during reproductive ages can affect fertility decisions, whereas bereavement after retirement implies the loss of crucial support for women as they age.

\section{Results}

\section{Child Death Conditional on a Woman's Survival}

We start by examining global trends in the cumulative frequency of child death over the life course of a woman aged $a$ by birth cohort and UN Sustainable Development Goals region (a list of country grouping and the full country results for the 1950-2000 annual cohorts are in the online appendix). The reader can query country-level results from the purpose-built web application (Alburez-Gutierrez 2021a). These initial results refer to an average woman conditional on her survival to a given age. As such, they do not account for the mortality of women or for the size and structure of the population. Overall, we project a sustained decline in the overall frequency of offspring mortality for younger cohorts of women, leading to a convergence toward lower values of child death at all ages (Figure 1). Conditional on the UN WPP projected rates, we expect the cumulative frequency of child death to decline at all ages by a factor of 9 between the 1955 and 2000 cohorts (averaging over all ages and countries). As we will show, this will occur at a global level and in each of the world regions separately.

Figure 1 Mean frequency of child death (top) and child survival (bottom) over the life course of two selected birth cohorts of women. The solid lines represent median values, and the bands represent the variability among countries in each region (40th and 60th percentiles). LATAM = Latin America. 


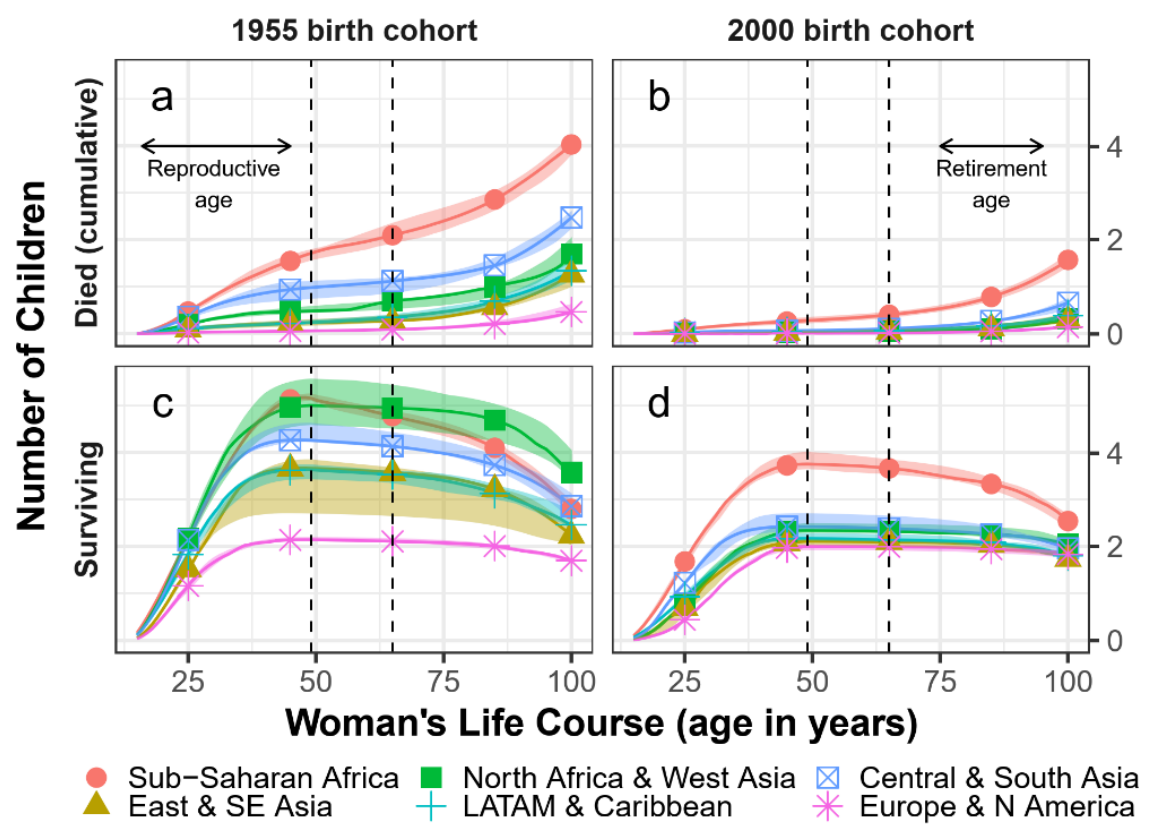

As a first step, we exemplify the decline by considering changes in the cumulative number of child deaths for a woman aged 65, which we assume to be the approximate age of retirement. Results are shown in Figure 1 (panels a and b), which shows the cumulative number of child deaths for an average woman in the 15-100 age range conditional on her survival to each age. An average woman born in 1955 will have lost 0.6 children by her 65 th birthday in 2020, but a woman born 45 years later, in 2000, will have experienced only 0.1 child deaths by the time she retires (assuming that retirement age is 65; online appendix, Figure S1, panel a). We also expect to see a reduction in the heterogeneity of the experience of child death over the life course both between and within world regions. We project that the frequency of child death will decline at a faster rate in regions where the values have historically been the highest, especially in sub-Saharan Africa. On average, a woman born south of the Sahara in 1955 will have lost 1.9 children by her 65th birthday, but a woman born in 2000 will have experienced the death of only 0.4 children by that same age. We expect to observe a similar decline among women of working 
ages (i.e., before age 65) in Central and South Asia: from 1 child death to only 0.1. These developments will reduce some of the striking disparities between the Global North (Europe, North America, Australia, and New Zealand) and the Global South that we observe for the 1955 cohort of women. Even so, we project that the experience of child death will continue to be more frequent in regions of the Global South than of the Global North. The gap in the cumulative number of child deaths by maternal age 65 will increase more than twofold between the least and the most affected countries over the projection horizon. ${ }^{1}$ Figure 2 shows the spatial variability in the lived experience of parental bereavement for women who are leaving formal employment in 2020. The lighter colors highlight the countries where an average woman currently aged 65 will have experienced the highest number of offspring deaths throughout her life and up to that age.

Figure 2 Cumulative number of child deaths experienced by an average woman aged 65 in 2020 (i.e., born in 1955) in different countries. Higher values indicate a higher frequency of child death, conditional on the woman's survival to age 65 .

${ }^{1}$ Women born in 1955 in Niger, which is the country most affected for that cohort, experienced 73 times moreoffspring deaths during their working ages than women of the same cohort in Sweden, which is the least affected country (Niger: 3.2 child deaths by age 65; Sweden: 0.4 deaths by age 65). Women born in 2000 in Chad, which is the most affected country for that cohort, are projected to experience 148 times more child deaths than their counterparts in Singapore by the time they retire from formal employment (in Chad, 1 child death by age 65 ; in Singapore, $<0.01$ child death by age 65$)$. 


\section{Cumulative numer of child deaths at age 65 for a woman born in 1955 (i.e., aged 65 in 2020)}

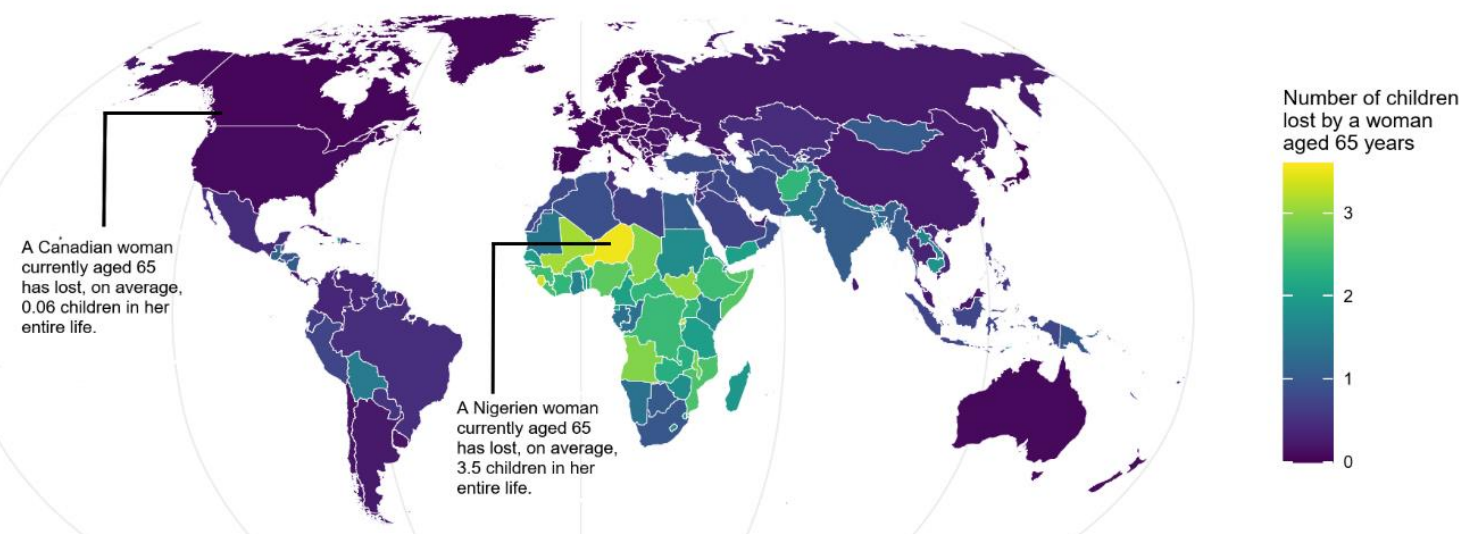

Keep in mind that these results are conditional on women's survival to a given age. The cumulative number of child deaths for a woman aged 65 , for example, should be interpreted as offspring loss for an average woman surviving to that age. Although this approach allows us to compare the experience of women of the same age in different settings, it ignores the role of mortality among potential mothers. We remove the condition on maternal survival in the next section, where we focus on population-level measures of offspring mortality.

We now consider the distribution of offspring mortality over a woman's life course in order to evaluate changes in the timing of child death. In contrast to our previous analysis, which examines the number of child deaths accumulated over the life course, we now focus on the noncumulative number of child deaths a woman is expected to experience at each age. The first difference of child death $(\Delta C D(a, c, n))$ can be thought of as the age-specific frequency of child loss over the life course of a hypothetical woman (i.e., surviving to age $a$ ):

$$
\Delta C D(a, c, n)=C D(a+1, c, n)-C D(a, c, n) .
$$

Globally, we find evidence of a postponement in the experience of offspring mortality to older ages (online appendix, Figure S1, panel C). Conditional on the demographic rates projected 
by the UN WPP, women in younger cohorts will increasingly be more likely to lose an adult child in old age than a young child during their reproductive ages. We exemplify this shift in the experience of child death to older ages by considering the distribution of offspring mortality in two key periods of a woman's life: before age 50 and after age 65 for a woman surviving to age 100. For every subsequent cohort, we project an overall decline in the rate of child death at all ages but particularly during women's reproductive ages, which effectively shifts offspring deaths from reproductive ages to retirement ages (Figure 3). A woman born in 1955 surviving to age 100 will experience 3.3 times more offspring deaths in her reproductive years than after retirement. A woman born in 2000, by contrast, will experience 8 times more offspring deaths in her retirement than in her reproductive years. This implies a reduction in the frequency of exposure to the deaths of young children for women over time (keeping in mind that an adult child could be 40 or 50 years old). We anticipate observing similar developments around the world, but we expect that the shift of child deaths to older ages will be more evident in the Global North. Figure 3 (panels a and b) shows the considerable reduction in the incidence of maternal bereavement during the mother's reproductive years by comparing women born in 1955 and 2000. A European woman born in 2000 and surviving to age 100 can expect to experience 15 times more offspring deaths after retirement than during her reproductive life. This figure is 8 times for a Latin American woman and only 4 times for a woman born south of the Sahara.

Figure 3 Timing of child death over the life course for two female birth cohorts: first difference of child death (top) and burden of child death (bottom, in millions). The solid lines show the regional median and the bands the 40th and 60th percentiles within each region. LATAM = Latin America. 


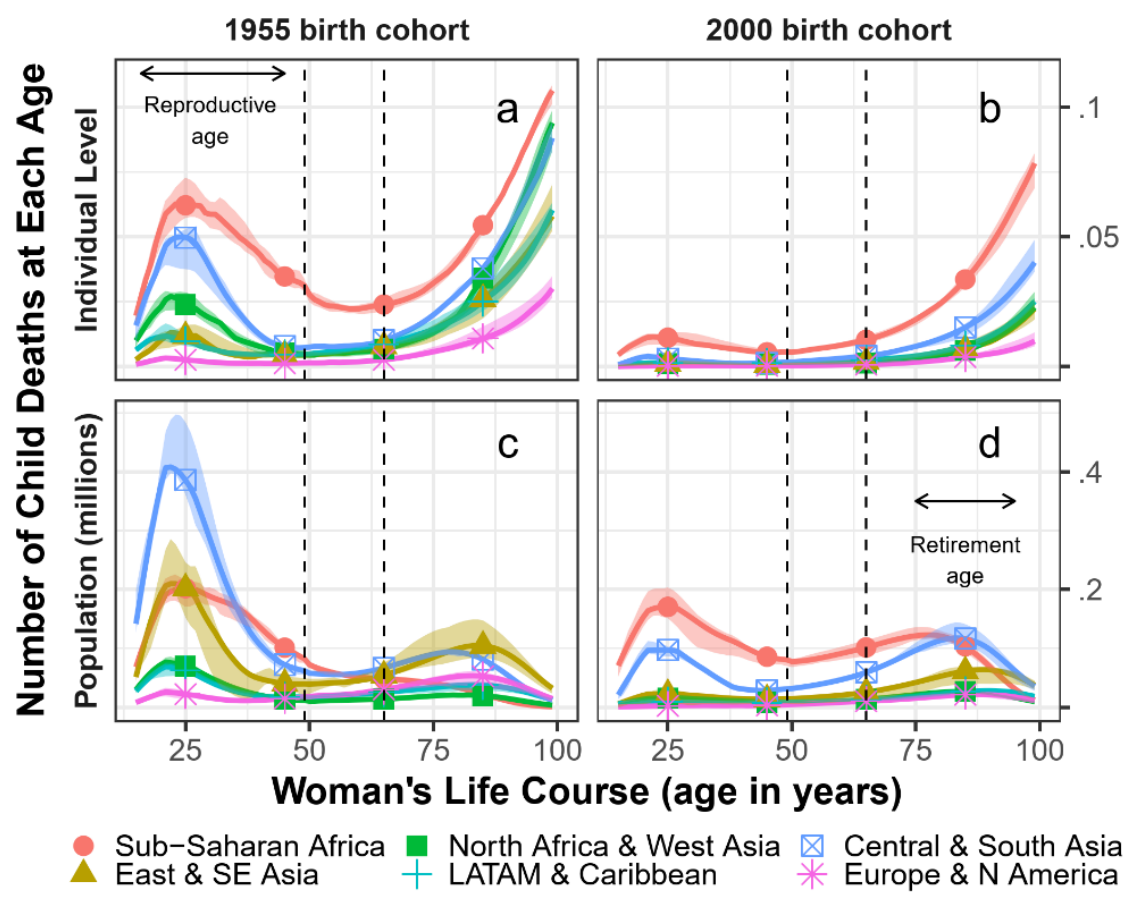

\section{Child Death at a Population Level}

Our individual-level analyses have so far focused on the distribution of offspring mortality over the life course of a woman while ignoring the role of mortality among women and the size of the cohorts into which these women are born. We now estimate population-level measures of offspring mortality by accounting for the fact that the prospective mothers in our analyses are also exposed to mortality throughout their lives. The burden of child death $(B C D)$ estimates how many offspring deaths would be experienced by all women born in cohort $c$ at each age $a$ if they were exposed to the life table mortality corresponding to their birth cohort. We define this as $B C D(a, c, n)=w(a, c, n) \Delta C D(a, c, n)$, where $w(a, c, n)$ is the age distribution of women or the number of women from birth cohort $c$ left alive at age $a$ in country $n$. Essentially, we weight the age-specific rate of child death $\triangle C D$ by the survivorship column of a cohort life table with a starting population (i.e., radix) equal to the initial size of each female birth cohort, which decreases according to a mortality function defined by a woman's country and cohort of birth. As 
a result, this measure does not focus on an average woman but instead on the experience of an entire female cohort. As we will show, the population-level analyses provide evidence of the two trends discussed so far: a reduction in the overall frequency of child death and a postponement of the experience of child death to older ages.

We start by quantifying the magnitude of the shift of the experience of child death to older ages. To do so, we consider how offspring deaths will be distributed over the life course of women, in particular during their reproductive ages (15-49) and after retirement, at age 65 (Figure 3, panels c and d). Women born in 1955, who will retire in 2020, experienced most of the deaths of their offspring during their reproductive ages. Of the 32 million child deaths that women born in 1955 will experience throughout their lives, $62 \%$ will happen before they reach age 50 , and only $28 \%$ will occur after they reach age 65 . However, starting with the 1985 cohort, women will be more likely to lose an adult child after age 65 than a young child before age 50 , reversing a long-standing historical trend. For women born in 2000, offspring deaths will be mostly concentrated in later life. The 20 million offspring deaths that women in this cohort are projected to experience will mostly occur after they retire (49\% of all child deaths) rather than during their reproductive ages (only $38 \%$ of all child deaths).

The shift of maternal bereavement to older ages will not be homogeneous across countries and regions. Consider the percentage of lifetime offspring deaths that will be experienced after age 65 by a woman born in 1955 (online appendix, Figure S3). In countries such as Mali, for example, an average woman who is 65 years old in 2020 has already lost $92 \%$ of all the children she is projected to lose during her lifetime. By contrast, an average woman in Japan who turns 65 in 2020 is far more likely to lose a child after this point in her life than before it. 
In short, we project a decline in the burden of adult child death over the entire life course in most world regions and an increase in the mean age at which women experience the death of a child in all world regions. The likelihood of a mother experiencing the deaths of her adult children is projected to remain at relatively high levels only in Central and South Asia and subSaharan Africa because of a combination of improved female survival, relatively high mortality for children, and high fertility.

We quantify the reduction in the overall frequency of child death around the world by estimating the cumulative number of child deaths experienced by different cohorts of women. This is the sum of the burden of child death over age for women in a given birth cohort, up to age 100 , which is the upper age limit of our models. The cohort burden of child death is $C B C D(-, c, n)=\sum_{x=15}^{x=100} B C D(x, c, n)$. This measure provides a sense of the magnitude of offspring mortality for different cohorts of women by estimating the aggregate number of child deaths that an entire female birth cohort would experience over its complete life course.

We anticipate a massive reduction in the total number of child deaths that subsequent cohorts of women will experience around the world. Consider Figure 4, in which movement along the vertical axis represents a change in the quantity of child death over time and horizontal movement represents a change in the cohort size of the prospective mothers who will experience these deaths. The values in this plot would increase along a 45-degree line if the population and the burden of child death were to increase at the same rate. The global cohort burden of child death will be 1.6 times lower for women born in 2000 than for women born in 1955 (20 and 32 million deaths, as mentioned earlier), despite the fact that the 2000 cohort of women is projected to be 1.3 times larger than the 1955 cohort. Nowhere will these changes be more radical than in Asia. We estimate that the cohort of women born in 1955 in Eastern and Southeastern Asia will 
experience a total of 7.2 million offspring deaths throughout their lives. The 2000 cohort can expect to experience only 2.6 million offspring deaths over their lifetimes.

We project equivalent declines for Central and South Asia and most other world regions. The global burden of child death will increasingly shift to sub-Saharan Africa, a region projected to represent more than one-third of the world population by 2100 . This is the only region where we expect the cohort burden of child death to increase for the more recent cohorts of women. Of the 32 million offspring deaths that women born in 1955 will experience, $22 \%$ will be experienced by women born in sub-Saharan Africa. However, of the 20 million offspring deaths projected for the 2000 cohort of women, $43 \%$ will be experienced by women in sub-Saharan Africa. This remarkable pattern results from persistently high levels of young offspring mortality coupled with higher levels of adult offspring mortality in the region. Rising life expectancy and relatively high levels of fertility in sub-Saharan Africa will mean that more women will live to see their children die in adult age. The incidence of child death will be comparatively low in the Global North, Latin America, North Africa and West Asia, and Eastern and Southeastern Asia. The relative contributions of these regions to the global burden of child death will continue to decrease in tandem with their future contributions to global population change.

Figure 4 Relationship between the cohort burden of child death (vertical axis, median valuesin millions) and the size of cohorts. The cohort burden of child death is the number of child deaths accumulated by all women in a given birth cohort and region throughout their lives. The 45degree line indicates the trajectory where cohort size and cohort burden of child death change by the same amount. LATAM = Latin America. 


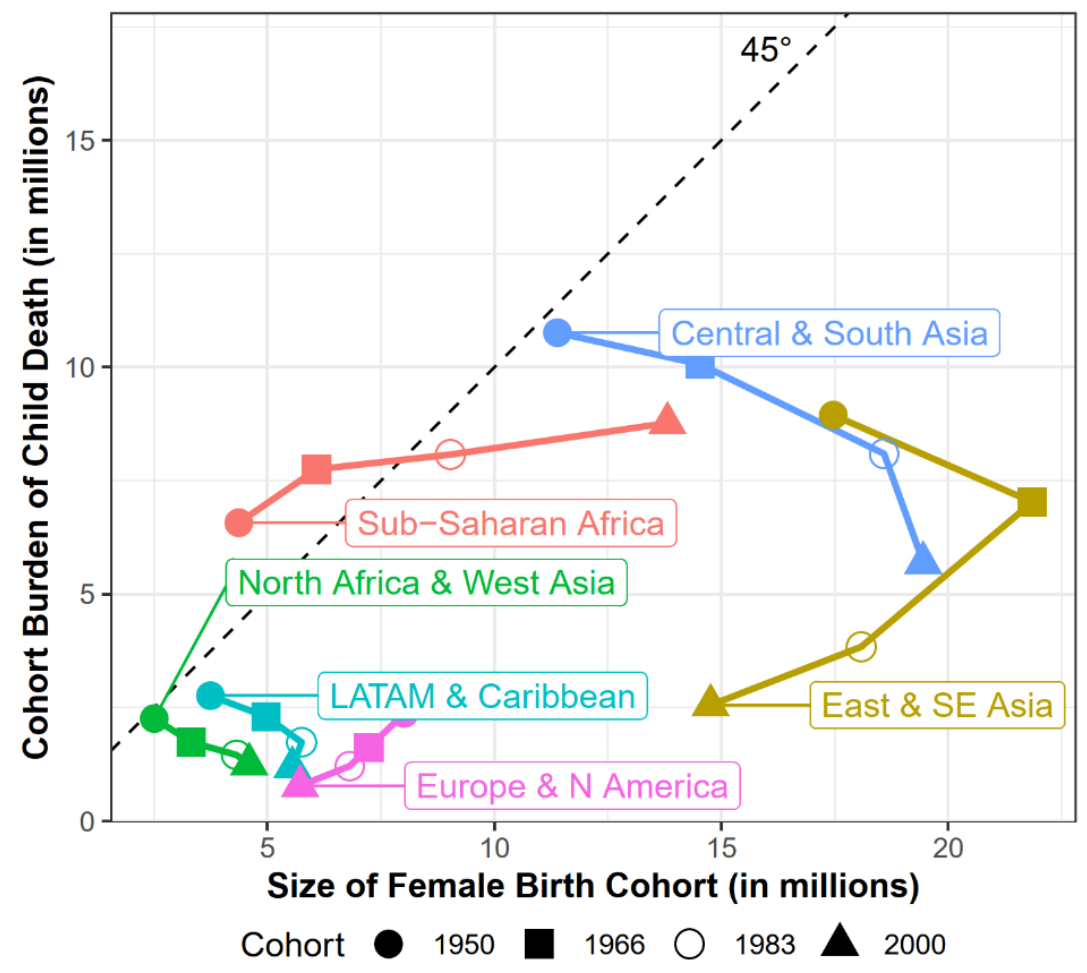

\section{Child Survival Conditional on Woman's Survival}

We now consider child survival: the mean number of children currently alive over a woman's life. Rearranging Eq. (1) shows that child survival is the result of subtracting the cumulative number of child deaths from the number of children ever born to a woman $a$ years old. Those familiar with the GKP equations will recognize this as the expected number of surviving children, a value that depends on the interaction of age-specific fertility and mortality rates over multiple cohorts. Globally, we expect to observe a reduction in the levels of child survival over a woman's life course (online appendix, Figure S1, panel B), reflecting the decline in the global TFR anticipated by the UN WPP projections. The latter trend results from the assumption of a convergence to replacement fertility levels built into the UN projection models (Alkema et al. 
2011). As we noted earlier, younger cohorts of women can expect that fewer of their children will die. Most of the anticipated change in child survival will be concentrated in the Global South: the projected demographic stability in Europe and North America will mean that child survival will change little between the 1950 and 2000 cohorts (Figure 1, panels $\mathrm{c}$ and d). The TFR in North Africa and West Asia is expected to fall sharply over the projection horizon, which explains the noticeable decline in the levels of child survival between the two birth cohorts. The high levels of child survival projected for women in sub-Saharan Africa in both cohorts result from the combination of persistent high fertility and significant improvements in mortality in the region.

\section{Child Survival Accounting for the Mortality of Women}

Child survival is particularly important if women expect to draw on the resources provided by their remaining children at older ages. We first examine offspring availability after retirement by estimating the share of a woman's progeny who will survive to celebrate her 65th birthday. We document an encouraging global trend: $95 \%$ of the children of women born in 2000 will still be alive when these women retire, up from $85 \%$ for the 1955 cohort. However, this positive trend masks wide gaps, and we project that inequalities in child survival across and within regions will persist in the future. Women in the Global North can expect that more than $99 \%$ of their children will survive until they reach age 65 . In Bolivia, women born in 1955 can expect only $74 \%$ of their children to be alive by the time they retire, a share that is well below the average for women in neighboring Argentina (93\%), Paraguay (89\%), and Brazil (86\%). Similar disparities between neighboring countries are evident in Cambodia (69\%), Yemen (76\%), and Rwanda (61\%), to name only a few. Nevertheless, in all world regions, there will be general progress toward improvements in child survival at older ages. For women born in 2000, the gap between the best- 
and worst-performing countries will be one-quarter as large as it was for women born in $1955 .^{2}$

We examine offspring availability at very old ages by considering the number of children expected to outlive their mothers, as seen from the perspective of a prospective mother.

Rearranging Eq. (1), we approximate offspring availability as the expected number of children surviving for a woman aged $e_{0}$, the female cohort life expectancy at birth in country $n$ and cohort $c$, or $C S\left(a=e_{0}, c, n\right)$. This is a broad approximation of the mean number of children whose lifespan will be, on average, at least as long as the lifespan of an average woman of the mother's cohort (under the simplifying assumption that all women will die when they reach the life expectancy of their cohorts). Globally, the number of children expected to outlive their mothers is projected to decrease by a factor of 3 over the projection horizon. An average woman in 1955 could expect 3.8 of her own children to live longer than she does. For a woman in the 2000 cohort, this number will be only 2.5 (online appendix, Figure S2, panel A). This global decline is partially explained by the projected fall in the TFR, but it is also influenced by the changing mortality regimes affecting women and children. Plateaus or increases in the number of children expected to outlive an average woman (e.g., Europe after 1980) result from improved life expectancy and, to a lesser extent, higher fertility. This pattern is visualized in Figure 5 (panel a), where the vertical axis represents the absolute number of children expected to live longer than an average woman in each world region. We expect the largest decline to occur in North Africa and West Asia, where women will go from having 5 to 2.3 surviving children, reflecting the expected

${ }^{2}$ The difference between the best- and the worst-performing countries will shrink from $79 \%$ for the 1955 cohort (the share of a woman's progeny who survive to her retirement is $55 \%$ in Sierra Leone, but $98 \%$ in Sweden) to only $26 \%$ for the 2000 cohort (the share of a woman's progeny who survive to her retirement is $79 \%$ in Chad but $>99 \%$ in Spain). 
fall in fertility between the 1955 and 2000 cohorts. We project consistently high values for sub-

Saharan Africa, where a woman born at the turn of the century will have, on average, 3.7

surviving children by the end of her life, down from 5 for a woman born in 1955 .

Figure 5 Absolute and relative number of children expected to live longer than an average woman. The solid lines represent regional median values, and the bands represent the variability among countries in each region (40th and 60th percentiles). LATAM = Latin America.

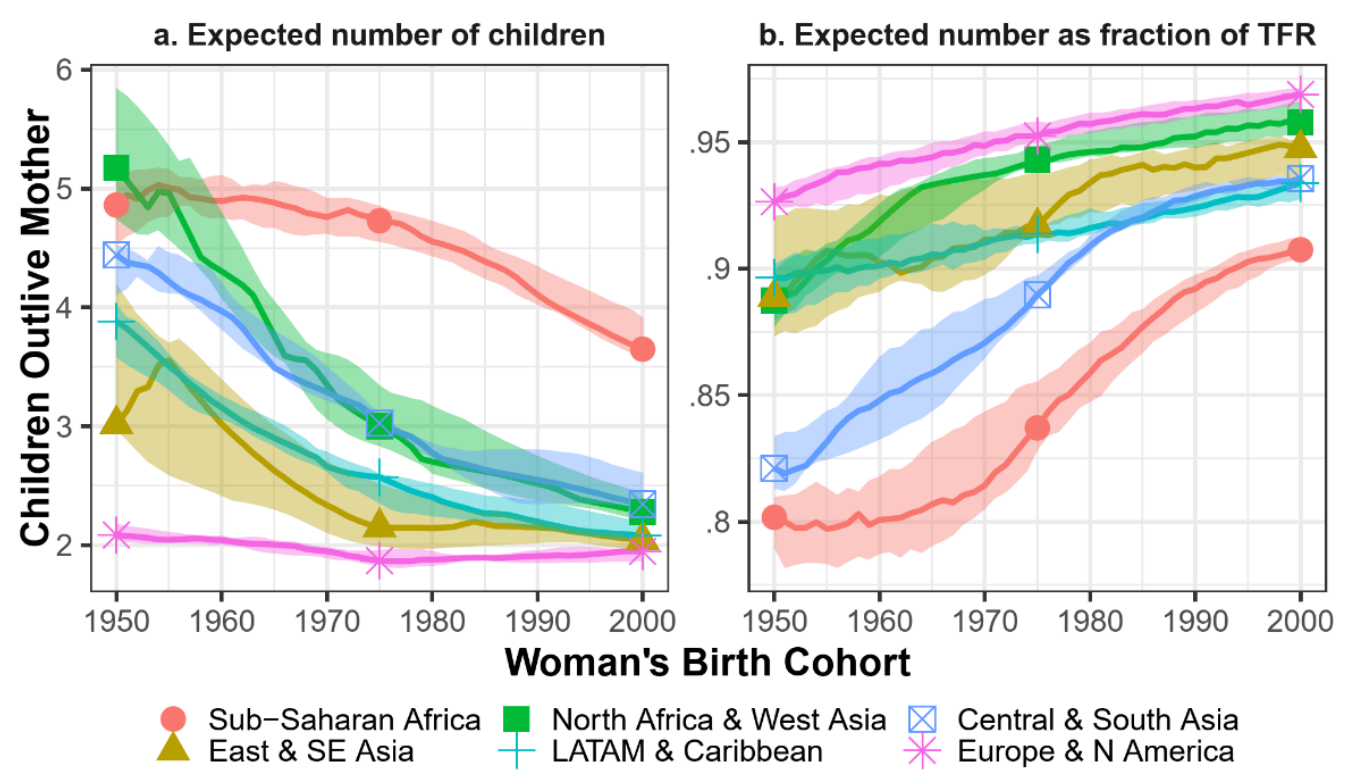

The number of children expected to outlive a woman is an informative measure, but it is heavily dependent on the prevailing fertility levels. We evaluate reductions in the accumulated experience of offspring mortality over a woman's life course by focusing on the fraction of children who will outlive their mothers (FOM). This measure makes it possible to compare levels of child survival for women in different regions while holding fertility levels constant. We obtain it by weighing the number of children expected to outlive an average woman by $\operatorname{CTFR}(-, c, n)$, the cohort total fertility rate of a woman's cohort $c$ in country $n$ : 


$$
\operatorname{FOM}(-, c, n)=\frac{\operatorname{CS}\left(e_{0}, c, n\right)}{\operatorname{CTFR}(-, c, n)}
$$

Globally, we project that the fraction of children expected to outlive their mothers will increase, on average, from $89 \%$ to $95 \%$ between the 1955 and 2000 cohorts (online appendix, Figure S2, panel b). The increasing relative availability of children at very old ages is shown in Figure 5 (panel b), where the vertical axis represents the share of a woman's progeny expected to outlive her. We anticipate more pronounced improvements in the Global South, where women historically could expect to lose a relatively high share of their offspring throughout their lives.

We document considerable regional variability in the availability of children at very old ages for women born in 1955 (online appendix, Figure S4). Women born in sub-Saharan Africa will go from losing 1 in 4 of their children to losing only 1 in 10 over the projection horizon, on average. This pattern contrasts with trends in Europe and North America, where women already experience high levels of child survival over the life course. Between the 1955 and 2000 cohorts, women in Australia and New Zealand will go from seeing 94\% of their children survive to experiencing the survival of $97 \%$ of their children. Although we project that these regional inequalities will persist in the foreseeable future, we estimate that the gap between the best- and worst-performing country will decline by $19 \%$ over the projection horizon. ${ }^{3}$

\section{Sensitivity Analysis}

We run our analyses again under different assumptions about future demographic change (Figure 6). For fertility, we use the "low variant" and "high variant"; for mortality, we use the lower and

\footnotetext{
${ }^{3}$ The difference between the countries experiencing the lowest and the highest levels of lifetime offspring child survival was $45 \%$ for the 1955 cohort (66\% for Rwanda and $96 \%$ for Singapore) but will be only $18 \%$ for the 2000 cohort( $84 \%$ for Chad and $98 \%$ for Iceland).
} 
upper 95\% projection interval (UNDESA 2019). We estimate the cumulative number of child deaths for women born in 2000 and surviving to age $a$ (Eq. (1)) in Guatemala, a country with relatively high fertility and mortality rates. Readers can explore other countries and regions in the companion web application (Alburez-Gutierrez 2021a). Figure 6 shows the four possible combinations of these variants and, for reference, equivalent estimates from the medium variant (used in the main text) and a "stable variant," defined as the expected number of child deaths in a stable population where rates remain fixed at the values observed for the 2000 cohort (i.e., a traditional GKP approach).

Figure 6 Sensitivity analysis: Cumulative child loss for a Guatemalan woman born in 2000 under different assumptions of future fertility and mortality (solid line). "Low mortality" is the UN WPP's lower 95\% projection interval, and "high mortality" is the upper 95\% projection interval.

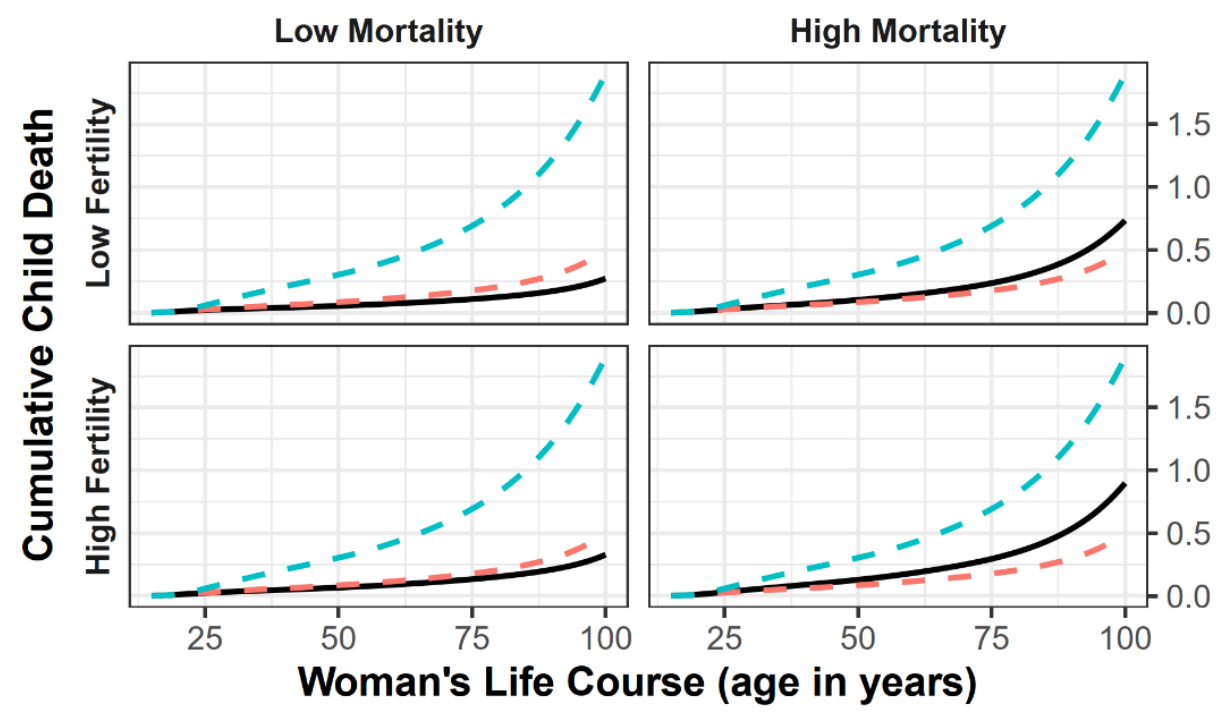

Reference variants - - Medium - - Stable

In general, our sensitivity analysis finds that the main patterns described earlier still hold under different assumptions of future demographic change. As expected, a high-mortality, highfertility variant produces higher estimates of cumulative child death, and the opposite is true for a 
low-fertility, low-mortality variant. A major concern was that the assumption of fertility convergence by 2020 in the medium fertility scenario would drive our results. However, the sensitivity analysis suggests that the choice of future mortality trajectories is more important. Finally, a traditional GKP approach, in which demographic rates are not allowed to change over time, overestimates cumulative child loss considerably compared with all other scenarios because it does not account for the projected decline in mortality and fertility in most world countries.

\section{Discussion}

We investigated how the projected changes in population dynamics will affect the lived experience of child death for younger cohorts of women. In doing so, we built on and extended existing work on the consequences of demographic change for maternal bereavement (Uhlenberg 1980, 1996). Our analyses focused on cumulative offspring mortality and on the distribution of offspring mortality over the life course. The study covered the entire world and documented regional and country heterogeneity. World regions differ widely in terms of their past, present, and projected demographic characteristics. By taking into account the demographic particularities of each world region, we showed that the expected demographic changes will affect the experience of child death in ways that are both regular and consistent. In this section, we discuss the implications of our main findings and their limitations, as well as show how they relate to demographic theory.

Overall, we projected a general decrease in the frequency of child death over the life course of women born in more recent years. Thus, given the future demographic trajectories projected by the UN WPP, the experience of child death will be increasingly uncommon among younger cohorts of women all around the world. This is partly because the demographic 
projections anticipate a reduction in global fertility, which in turn implies that fewer children will be at risk of dying. We showed that although the North-South divide will shrink considerably, international inequalities in the experience of offspring mortality will continue to affect women born at the turn of the twentieth century. Globally, most young child deaths will be experienced by women in Central and South Asia and sub-Saharan Africa as a result of population growth and persistently high levels of mortality and fertility. The decline in the burden of child death over the projection horizon will be particularly dramatic in Asia. As a result, although the death of a young child will be a rare event for North African or North American women, it will continue to be a distressing reality for many women in sub-Saharan Africa.

The projected global population dynamics will also affect the timing of child death over a woman's life course. Given equivalent levels of fertility, more rectangular survival curves with deaths compressed around the mean age at death will contribute to the aging of generational relationships (Murphy 2011), and the experience of offspring mortality will be shifted to older ages. Thus, offspring mortality, which has long been most likely to occur in women's reproductive years, will be increasingly experienced by women after retirement. We anticipate that for women in more recent birth cohorts, child death will increasingly mean the death of an adult child, not a young child. This phenomenon is expected to occur if period child mortality rates continue to decline over the course of the century, even as fertility converges toward replacement level. These trends are characteristic of aging populations. Given sufficient time, we expect them to hold at the global and the regional levels. Furthermore, countries in all regions will become more similar to one another over time, which will reduce the global and regional heterogeneity of the timing of child death over the life course of women. 
The global burden of child death is projected to decline among younger cohorts of women in all regions but sub-Saharan Africa. Adjusting our estimates for population structure, we found that women around the world will be increasingly likely to lose an adult child rather than a young child. In absolute terms, we expect that most adult child deaths will be experienced by women in sub-Saharan Africa; Central and South Asia; and, to a lesser extent, Eastern and Southeastern Asia. These developments should be accompanied by the establishment of robust systems of social care and support for the old. The death of an adult child can result in the loss of crucial social and material support for older women (Hendrickson 2009; Lee 2013). The consequences can be more severe following the death of an only child, which is a growing risk for women in regions with very low fertility (Espinosa and Evans 2013; Li et al. 2003).

Our study has four main limitations. First, the formal demographic approaches that we used to generate estimates ignore intergenerational correlations. Positive correlations between the fertility of mothers and the mortality of children could, for example, imply that women who give birth to many children also have children who are at higher risk of dying. Not accounting for these correlations may affect estimates of offspring mortality in some world regions. Based on preliminary testing with register data for Sweden, we expect that these correlations are of second-order importance in lower-mortality enclaves and do not affect the trajectories of our estimates significantly. We corroborated this by comparing our estimates with equivalent values derived from DHS for 31 countries in sub-Saharan Africa (Smith-Greenaway and Trinitapoli 2020), standardizing both measures to make them comparable. ${ }^{4}$ Our estimates of maternal

\footnotetext{
${ }^{4}$ Angola, Benin, Burkina Faso, Burundi, Cameroon, Chad, Democratic Republic of the Congo, Ethiopia, Gabon, Gambia, Ghana, Guinea, Kenya, Lesotho, Liberia, Malawi, Mali, Mozambique,
} 
offspring mortality for mothers aged 45-49 are highly consistent with the aforementioned empirical estimates, with a median absolute difference of 0.05 . This discrepancy is due to error associated with our formal method or the input demographic rates from the UN WPP as well as biases in the survey data (DHS), which can underestimate maternal bereavement considerably (Smith-Greenaway and Trinitapoli 2020). Nevertheless, our model-based approach has important advantages when applied to low- and middle-income settings without high-quality data collection systems. Our analyses used 150 years of demographic data (1950-2100, including demographic projections after 2019) to characterize the experience of child death over the entire life course of women in every country of the world. Studies using household surveys, such as the DHS or the Multiple Indicator Cluster Survey, would be unable to replicate this analysis in full. This is particularly true of estimates of adult child mortality, which require life course data for both women and their children that surveys do not collect.

Second, the kin-cohort method ignores the clustering of child mortality by assuming homogeneity in the experience of offspring mortality, but previous studies have shown considerable within-country inequality in the exposure to death (Umberson et al. 2017). The model assigns an equal probability of experiencing child death to all women even though, in practice, most offspring deaths may be experienced by only a small group of women. We expect our focus on average women to balance out some of this bias. Future work can produce subnational estimates of offspring death.

Third, our analyses focus on the experience of an average woman, not an average mother, and do not factor in childlessness, for which no comprehensive global data exist

Namibia, Niger, Nigeria, Republic of the Congo, Rwanda, Senegal, Sierra Leone, South Africa, Tanzania, Togo, Uganda, Zambia, and Zimbabwe. 
(Kreyenfeld and Konietzka 2017). Future studies could leverage register and survey data or demographic microsimulation to extend this line of work.

Fourth, the results of any regional analysis depend on how countries are aggregated. To empower the reader to aggregate countries in different ways than the ones we showed here, we developed a web application that allows users to generate and visualize alternative regional estimates (Alburez-Gutierrez 2021a).

This study has clear policy implications. We showed evidence of an unprecedented aging of the experience of parental bereavement for women around the world, a process that had been hitherto only theorized in the demographic literature (Livi Bacci 1997). These findings provide policy-makers with estimates of the current and the future dimensions of the problem in all countries by cohort and age. Our analysis clarifies the need for localized policy responses to address the issue of parental bereavement. Despite global improvements in child mortality, the burden of child loss will remain unchanged in some regions in the foreseeable future. The burden of child death in sub-Saharan Africa is projected to increase rather than to decrease at most ages, but especially in later life, from 7 to 9 million deaths over the projection horizon. We project a similar increase in the burden of child death for older parents in Central and South Asia. These findings underpin the need for pertinent measures to address the public health consequences of parental bereavement around the world, especially when child death affects older parents in retirement.

\section{Conclusion}

Losing a child is a traumatic event that has been linked to negative outcomes for parents in general and for mothers in particular. We unpacked the complex interactions between global demographic changes - that is, reductions in young child mortality, increases in life expectancy, 
reductions in total fertility, and postponement of births - and the experience of offspring mortality over a woman's life course. Accounting for age structure and population size, we estimated the total number of child deaths expected by world region. The exposure to child death is a pervasive yet often unnoticed form of international inequality that varies predictably according to the demographic regime prevailing in a given population. We demonstrated that there is an opportunity to narrow this historical gap between the Global North and the Global South in the future. We are edging toward a world based on a natural chronological hierarchy of death, where the death of a child — and particularly of a young child — will be an extremely uncommon experience for women. Some women are already living in this world, but many others will have to wait to benefit from it.

Acknowledgments We thank Chia Liu, Daniela Negraia, Emily Smith-Greenaway, Monica Alexander, and Yana Vierboom for useful comments. We thank Sarah Zureick-Brown for sharing her code from a previous study. The paper was presented at the Stockholm University Demographic Colloquium, the Work-in-progress Workshop of the MPIDR Lab of Digital and Computational Demography, and the conference of the British Society for Population Studies. We thank the anonymous reviewers for their constructive feedback.

\section{Data availability statement}

The code to reproduce the results and the complete country estimates are available online (Alburez-Gutierrez 2021b), as are the data used for the analysis (population.un.org/wpp/). Alternative results can be produced and downloaded using the online tool developed for this purpose (Alburez-Gutierrez 2021a).

\section{References}

Albuquerque, S., Pereira, M., \& Narciso, I. (2016). Couple's relationship after the death of a child: A systematic review. Journal of Child and Family Studies, 25, 30-53. 
Alburez-Gutierrez, D. (2021a). Women's experience of child death: A global demographic perspective (Interactive web application for paper). https://doi.org/10.17605/osf.io/2pq3d Alburez-Gutierrez, D. (2021b). Women's experience of child death: A global demographic perspective (Online supplementary materials for paper). https://doi.org/10.17605/osf.io/jdvhw

Alkema, L., Raftery, A. E., Gerland, P., Clark, S. J., Pelletier, F., Buettner, T., \& Heilig, G. K. (2011). Probabilistic projections of the total fertility rate for all countries. Demography, 48, 815-839.

Caldwell, J. C. (1978). A theory of fertility: From high plateau to destabilization. Population and Development Review, 4, 553-577.

Espinosa, J., \& Evans, W. N. (2013). Maternal bereavement: The heightened mortality of mothers after the death of a child. Economics \& Human Biology, 11, 371-381.

Goldstein, J.R. \& Lee, R.D. (2020). Demographic perspectives on the mortality of COVID-19 and other epidemics. Proceedings of the National Academy of Sciences 117, 2203522041.

Goodman, L. A., Keyfitz, N., \& Pullum, T. W. (1974). Family formation and the frequency of various kinship relationships. Theoretical Population Biology, 5, 1-27.

Hendrickson, K. C. (2009). Morbidity, mortality, and parental grief: A review of the literature on the relationship between the death of a child and the subsequent health of parents. Palliative \& Supportive Care, 7(1), 109-119.

Hug, L., Dharrow, D., Zhong, K., \& Danzhen, D. (2018). Levels and trends in child mortality: Report 2018. Washington, DC: World Bank Group.

Keyfitz, N., \& Caswell, H. (2005). Applied mathematical demography. New York, NY: 
Springer.

Kreyenfeld, M., \& Konietzka, D. (Eds.). (2017). Childlessness in Europe: Contexts, causes, and consequences. Cham, Switzerland: Springer International Publishing. https://doi.org/10.1007/978-3-319-44667-7

Lee, C., Glei, D. A., Weinstein, M., \& Goldman, N. (2014). Death of a child and parental wellbeing in old age: Evidence from Taiwan. Social Science \& Medicine, 101, 166-173.

Lee, R. (2011). The outlook for population growth. Science, 333, 569-573.

Lee, R. (2013). Intergenerational transfers, the biological life cycle, and human society. Population and Development Review, 38(Suppl. 1), 23-35.

Lee, R., \& Mason, A. (2011). Generational economics in a changing world. Population and Development Review, 37(Suppl. 1), 115-142.

Lesthaeghe, R. (2014). The second demographic transition: A concise overview of its development. Proceedings of the National Academy of Sciences, 111, 18112-18115.

Li, J., Precht, D. H., Mortensen, P. B., \& Olsen, J. (2003). Mortality in parents after death of a child in Denmark: A nationwide follow-up study. Lancet, 361, 363-367.

Livi Bacci, M. (1997). A concise history of world population (2nd ed.) (C. Ipsen, Trans.). Oxford, UK: Blackwell Publishers.

Margolis, R., \& Verdery, A. M. (2019). A cohort perspective on the demography of grandparenthood: Past, present, and future changes in race and sex disparities in the United States. Demography, 56, 1495-1518.

Meert, K. L., Donaldson, A. E., Newth, C. J. L., Harrison, R., Berger, J., Zimmerman, J., .. . Shear, K. (2010). Complicated grief and associated risk factors among parents following a child's death in the pediatric intensive care unit. Archives of Pediatrics \& Adolescent 
Medicine, 164, 1045-1051.

Murphy, M. (2011). Long-term effects of the demographic transition on family and kinship networks in Britain. Population and Development Review, 37, 55-80.

Oeppen, J. (2002). Enhanced: Broken limits to life expectancy. Science, 296, 1029- 1031.

Preston, S. H., Heuveline, P., \& Guillot, M. (2001). Demography: Measuring and modeling population processes. Malden, MA: Blackwell Publishers.

Reher, D. S. (2019). The aftermath of the demographic transition in the developed world: Interpreting enduring disparities in reproductive behavior. Population and Development Review. Advance online publication. https://doi.org/10.1111/padr.12266

Rogers, C. H., Floyd, F. J., Seltzer, M. M., Greenberg, J., \& Hong, J. (2008). Long-term effects of the death of a child on parents' adjustment in midlife. Journal of Family Psychology, 22, 203-211.

Rostila, M., Saarela, J., \& Kawachi, I. (2012). Mortality in parents following the death of a child: A nationwide follow-up study from Sweden. Journal of Epidemiology and Community Health, 66, 927-933.

Schoumaker, B. (2019). Male fertility around the world and over time: How different is it from female fertility? Population and Development Review, 45, 459-487.

Seltzer, J. A., \& Bianchi, S. M. (2013). Demographic change and parent-child relationships in adulthood. Annual Review of Sociology, 39, 275-290.

Smith-Greenaway, E., \& Trinitapoli, J. (2020). Maternal cumulative prevalence measures of child mortality show heavy burden in sub-Saharan Africa. Proceedings of the National Academy of Sciences, 117, 4027-4033.

Song, J., Floyd, F. J., Seltzer, M. M., Greenberg, J. S., \& Hong, J. (2010). Long-term effects of 
child death on parents' health related quality of life: A dyadic analysis. Family Relations, 59, 269-282.

Uhlenberg, P. (1980). Death and the family. Journal of Family History, 5, 313-320.

Uhlenberg, P. (1996). Mortality decline in the twentieth century and supply of kin over the life course. Gerontologist, 36, 681-685.

Umberson, D., Olson, J. S., Crosnoe, R., Liu, H., Pudrovska, T., \& Donnelly, R. (2017). Death of family members as an overlooked source of racial disadvantage in the United States. Proceedings of the National Academy of Sciences, 114, 915-920.

UNDESA. (2019). World population prospects 2019: Methodology of the United Nations population estimates and projections (Technical report). New York, NY: United Nations, Department of Economic and Social Affairs, Population Division.

Vaupel, J. W. (2010). Biodemography of human ageing. Nature, 464, 536-542.

Verdery, A. M., \& Margolis, R. (2017). Projections of White and Black older adults without living kin in the United States, 2015 to 2060. Proceedings of the National Academy of Sciences, 114, 11109-11114.

Volk, A. A., \& Atkinson, J. A. (2013). Infant and child death in the human environment of evolutionary adaptation. Evolution and Human Behavior, 34, 182-192.

Weitzman, A., \& Smith-Greenaway, E. (2020). The marital implications of bereavement: Child death and intimate partner violence in West and Central Africa. Demography, 57, 347371.

Wijngaards-de Meij, L., Stroebe, M., Schut, H., Stroebe, W., van den Bout, J., van der Heijden, P., \& Dijkstra, I. (2005). Couples at risk following the death of their child: Predictors of grief versus depression. Journal of Consulting and Clinical Psychology, 73, 617-623. 
Wilmoth, J. (2009). The lifetime risk of maternal mortality: Concept and measurement. Bulletin of the World Health Organization, 87, 256-262.

You, D., Hug, L., Ejdemyr, S., Idele, P., Hogan, D., Mathers, C., . . Alkema, L. (2015). Global, regional, and national levels and trends in under-5 mortality between 1990 and 2015, with scenario-based projections to 2030: A systematic analysis by the UN Inter-agency Group for Child Mortality Estimation. Lancet, 386, 2275-2286.

Zagheni, E. (2011). The impact of the HIV/AIDS epidemic on kinship resources for orphans in Zimbabwe. Population and Development Review, 37, 761-783. 


\title{
Supplementary Materials for Women's experience of child death over the life course: A global demographic perspective
}

\author{
Diego Alburez-Gutierrez, ${ }^{1 *}$ Martin Kolk, ${ }^{2}$ Emilio Zagheni ${ }^{1}$ \\ ${ }^{1}$ Laboratory of Digital and Computational Demography, \\ Max Planck Institute for Demographic Research, \\ Konrad-Zuse-Straße 1, 18057 Rostock, Germany \\ ${ }^{2}$ Stockholm University Demography Unit, \\ Stockholm University, Frescativägen, 11419 Stockholm, Sweden
}

*To whom correspondence should be addressed; E-mail: alburezgutierrez@demogr.mpg.de

\section{This PDF file includes:}

Supplementary text

Fig. S1. Global patterns of child death and child survival for women in three different birth cohorts

Fig. S2. Global trends in the absolute and relative number of children expected to live longer than their mothers

Fig. S3. Offspring deaths experienced during retirement ages as a share of the lifetime offspring deaths for women

Fig. S4. Children expected to outlive a woman turning 65 years old in 2020

Fig. S5. Number of children currently alive as a share of children ever born.

Data file A1. Full country results for measures: Child Death, Child Survival, First Difference of Child Death, and Burden of Child Death 
Data file A2. Full country results for measures: Children expected to outlive mother

\section{Supplementary text}

We conducted all analyses at the country level, but only report regional estimates in the main text. Our regional analyses group countries according to the United Nations Sustainable Development Goals (UN SDG) regions, which follow the M49 standard for area codes. Results for alternative country groupings can be produced using the purpose-built online tool (Alburez-Gutierrez, 2021a). Countries are grouped as follows. SUB-SAHARAN AFRICA: Burundi; Comoros; Djibouti; Eritrea; Ethiopia; Kenya; Madagascar; Malawi; Mauritius; Mayotte; Mozambique; Reunion; Rwanda; Seychelles; Somalia; South Sudan; Uganda; United Republic of Tanzania; Zambia; Zimbabwe; Angola; Cameroon; Central African Republic; Chad; Congo; Democratic Republic of the Congo; Equatorial Guinea; Gabon; Sao Tome and Principe; Botswana; Eswatini; Lesotho; Namibia; South Africa; Benin; Burkina Faso; Cabo Verde; Cote d'Ivoire; Gambia; Ghana; Guinea; Guinea-Bissau; Liberia; Mali; Mauritania; Niger; Nigeria; Senegal; Sierra Leone; and Togo. NORTHERN AFRICA AND WESTERN ASIA: Algeria; Egypt; Libya; Morocco; Sudan; Tunisia; Western Sahara; Armenia; Azerbaijan; Bahrain; Cyprus; Georgia; Iraq; Israel; Jordan; Kuwait; Lebanon; Oman; Qatar; Saudi Arabia; State of Palestine; Syrian Arab Republic; Turkey; United Arab Emirates; and Yemen. CENTRAL AND SOUTHERN ASIA: Kazakhstan; Kyrgyzstan; Tajikistan; Turkmenistan; Uzbekistan; Afghanistan; Bangladesh; Bhutan; India; Iran (Islamic Republic of); Maldives; Nepal; Pakistan; and Sri Lanka. EASTERN AND SOUTH-EASTERN ASIA: China; Hong Kong; China, Macao SAR; Taiwan; Dem. People's Republic of Korea; Japan; Mongolia; Republic of Korea; Brunei Darussalam; Cambodia; Indonesia; Lao People's Democratic Republic; Malaysia; Myanmar; Philippines; Singapore; Thailand; Timor-Leste; and Viet Nam. LATIN AMERICA 
AND THE CARIBBEAN: Aruba; Bahamas; Barbados; Cuba; Curacao; Dominican Republic; Grenada; Guadeloupe; Haiti; Jamaica; Martinique; Puerto Rico; Saint Lucia; Saint Vincent and the Grenadines; Trinidad and Tobago; United States, Virgin Islands; Belize; El Salvador; Guatemala; Honduras; Mexico; Nicaragua; Panama; Argentina; Bolivia (Plurinational State of); Chile; Colombia; Ecuador; French Guiana; Guyana; Paraguay; Peru; Suriname; Uruguay; and Venezuela (Bolivarian Republic of). AUSTRALIA/NEW ZEALAND: Australia and New Zealand. OCEANIA (EXCLUDING AUSTRALIA AND NEW ZEALAND): Fiji; New Caledonia; Papua New Guinea; Solomon Islands; Vanuatu; Guam; Kiribati; Micronesia (Fed. States of); French Polynesia; Samoa; and Tonga. EUROPE AND NORTHERN AMERICA: Belarus; Bulgaria; Czechia; Hungary; Poland; Republic of Moldova; Romania; Russian Federation; Slovakia; Ukraine; Channel Islands; Denmark; Estonia; Finland; Iceland; Ireland; Latvia; Lithuania; Norway; Sweden; United Kingdom; Albania; Bosnia and Herzegovina; Croatia; Greece; Italy; Malta; Montenegro; North Macedonia; Portugal; Serbia; Slovenia; Spain; Austria; Belgium; France; Germany; Luxembourg; Netherlands; Switzerland; and United States of America. Note that we consider Greenland to be a part of Denmark. 


\section{Additional results}
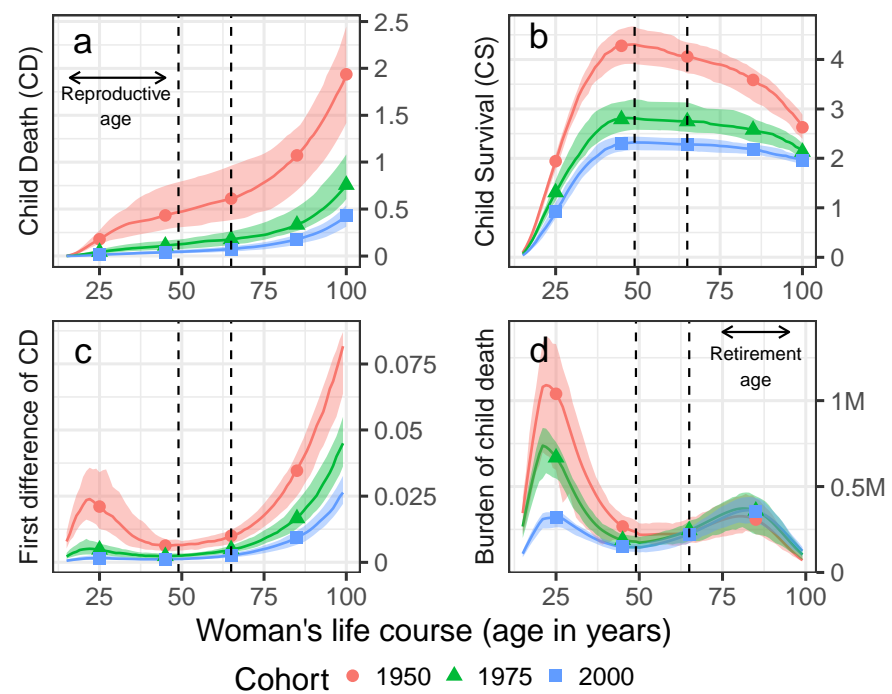

Figure S1: Global patterns of child death and child survival for women in three different birth cohorts. (A) Cumulative number of child deaths experienced by a woman reaching age $a$. (B) Total number of children surviving for a woman reaching age $a$. Values in the vertical axis represent the number of children 'currently alive'. (C) First Difference of Child Death $(\triangle C D)$ : number of child deaths experienced at each age $a$ by a woman reaching that age (i.e. conditional on female survival). (D) Burden of Child Death: total number of child deaths experienced by all women in a given birth cohort at each age $a$ (in millions). In all panels, the solid lines represent the global median values and the bands the variability among all world countries for each female cohort ( $40^{\text {th }}$ and $60^{\text {th }}$ percentiles). 


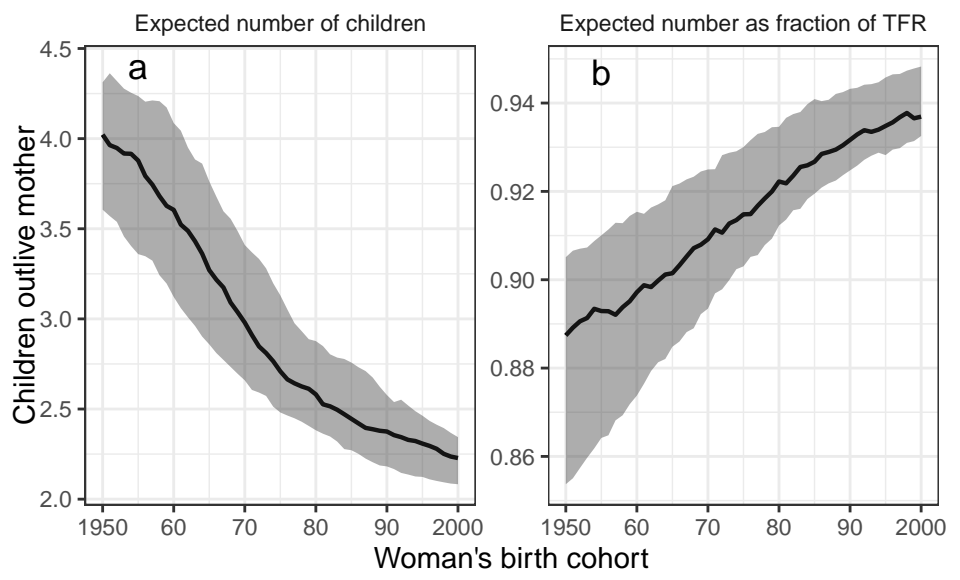

Figure S2: Global trends in the absolute and relative number of children expected to live longer than their mothers. (A) Number of children expected to outlive an average woman. Values in the vertical axis show the number of children alive at the time of a woman's death if she survives to the life expectancy in her cohort and country of birth. (B) Children expected to outlive a woman as a fraction of her cohort's TFR $(F O W)$. Higher values indicate that a larger fraction of a woman's offspring is expected to live longer than her. In all panels, the solid lines represent the global median values and the bands the variability among all world countries for each female cohort $\left(40^{t h}\right.$ and $60^{t h}$ percentiles). 
Child deaths experienced after age 65 by women born in 1955 (i.e. aged 65 in 2020)

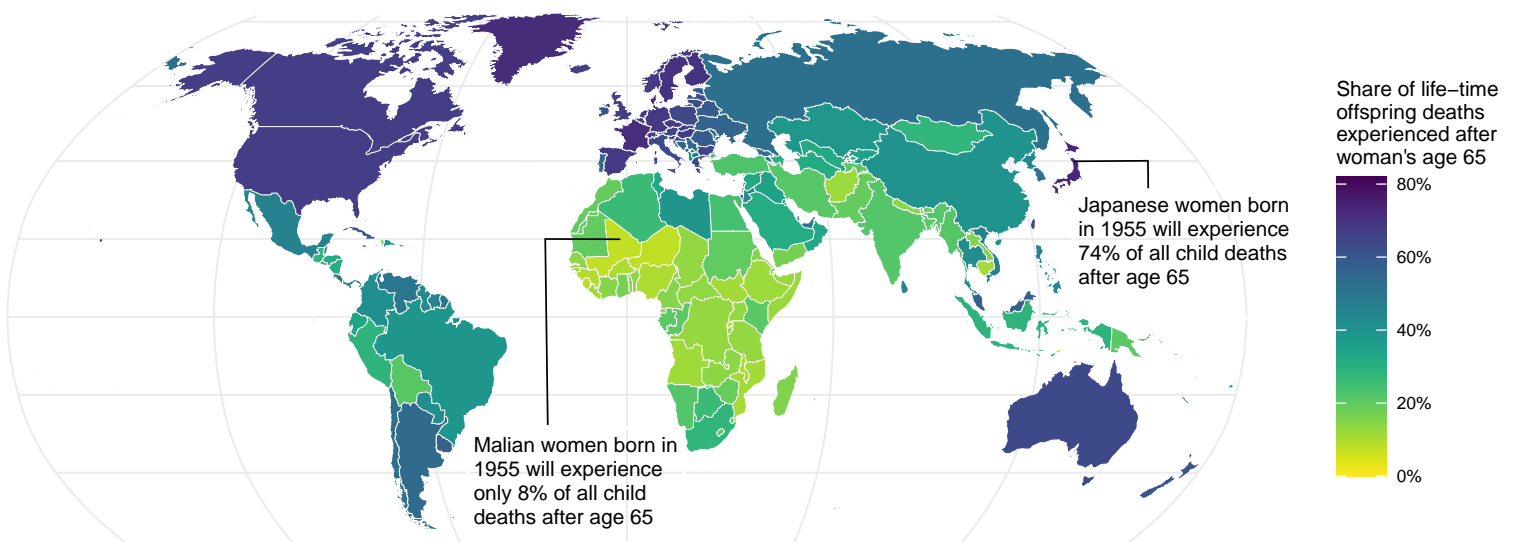

Figure S3: Offspring deaths experienced during retirement ages as a share of the lifetime offspring deaths for women. Higher values indicate a higher concentration of offspring mortality after women reach age 65 (country-level averages).

Percentage of children outliving an average woman born in 1955 (i.e. aged 65 in 2020)

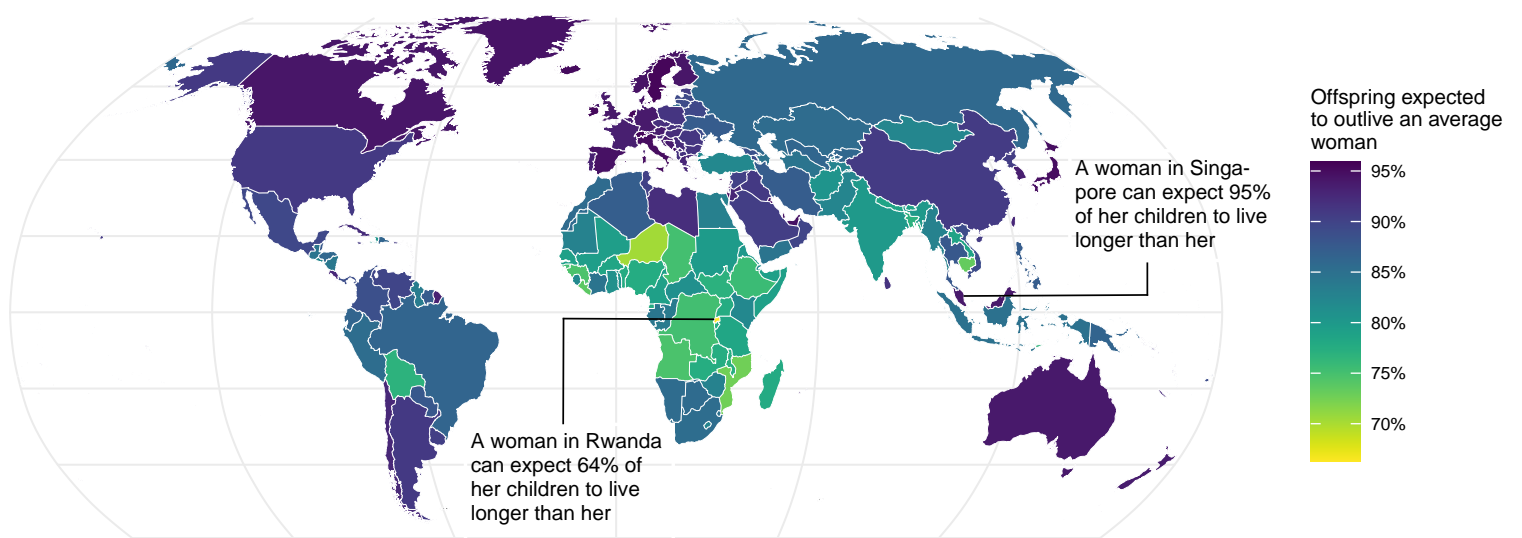

Figure S4: Children expected to outlive a woman turning 65 years old in 2020. Higher values indicate that a larger share of offspring of women born in 1955 will live longer than their mothers (country-level averages). 


\section{A visual summary}

Fig. S5 presents a visual summary of our two main findings: i.e., that the experience of child death will be reduced and parental bereavement will be postponed to older ages for more recent birth cohorts of women. For this, we consider the availability of children at all ages, and not only at the time of a woman's retirement or at the moment of her death as we did in the main text. Fig. S5 represents the offspring survival over the life course of an average woman, conditional on her own survival to each age. Each panel is composed of hundreds of pixels, the color of which indicates the percentage of a woman's offspring expected to survive up to that woman's age 'a' (vertical axis) according to the woman's birth cohort (horizontal axis). The solid lines are percentile lines showing the ages at which an average woman in each cohort can expect at least $50,60,70,80,90,95$, and $99 \%$ of her children to still be alive. Reading the plots vertically reflects the experience of a given cohort over age; the pixels are always light blue at the bottom of the graph (when women are young) and are closer to fuchsia at the top (when women are very old and more likely to have experienced bereavement). Reading the plots horizontally reveals changes in child availability over multiple cohorts of women. The reduction in the frequency of child death at all ages is exemplified by the prevalence of light-blue pixels on the right handside of each panel, which indicate a lower incidence of child death over the life course for subsequent birth cohorts of women. The shift of the experience of bereavement to older ages is demonstrated by the upward trend of the percentile lines. An average woman born in 2000, for example, will be considerably older by the time she experiences the same levels of bereavement as a woman born in 1955, or she will not experience these levels of bereavement at all in the course of her life. 


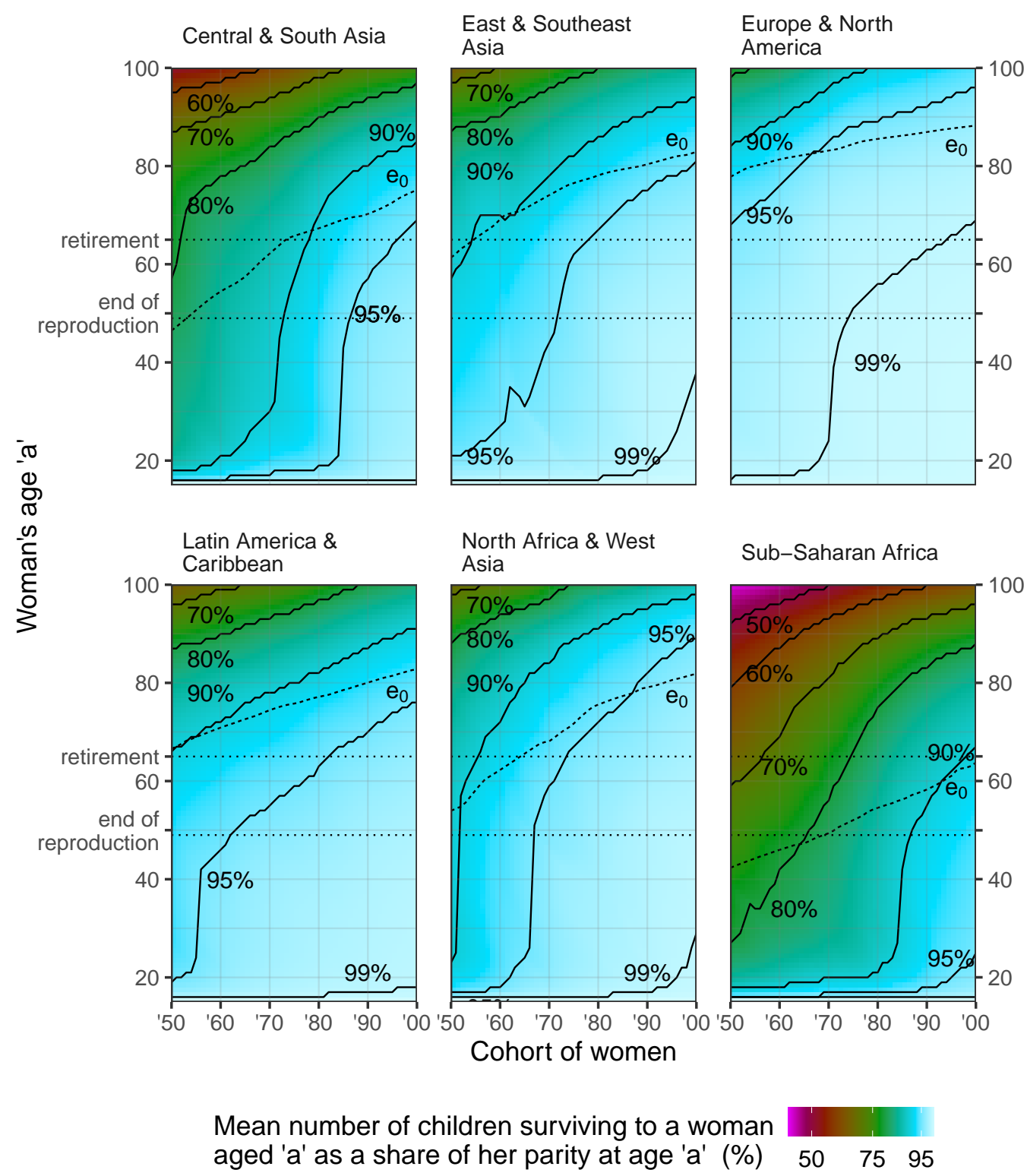

Figure S5: Number of children currently alive as a share of children ever born. Solid lines show the ages at which we would expect various percentiles of a woman's progeny to still be alive. Dotted lines mark the regional life expectancy at birth in years for an average woman in each cohort and region.

\section{Data files}

Data files A1 and A2 include estimates for all countries, regions and birth cohorts and ages.

Download from the project's Online Supplementary Materials (Alburez-Gutierrez, 2021b). 


\section{Data file A1. Full country results for measures: Child Death, Child Survival, First Dif- ference of Child Death, and Cohort Burden of Child Death Full results for the following measures:}

- Child Death: Eq. 1 in the main text and Fig. 1 (panels a and b).

- Child Survival: Eq. 1 in the main text and Fig. 1 (panels c and d).

- First Difference of Child Death $(\Delta C D)$ : Eq. 2 in the main text and Fig. 3 (panels a and b).

- Burden of Child Death: Fig. 3 in the main text (panels c and d).

The database, derived from the empirical analyses carried out in this paper, gives single-year and single-age estimates for all countries in the world corresponding to the 1950-2000 female birth cohorts (selected cohorts and ages). Approximate size: $1 \mathrm{MB}$.

\section{Data file A2. Full country results for measures: Children expected to outlive mother Full} results for the following measures:

- Number of children expected to outlive an average woman: Fig. 5 in the main text (panel a).

- Fraction of children that will outlive their mothers: Eq. 3 in the main text and Fig. 5 (panel b).

The database, derived from the empirical analyses carried out in this paper, gives single-year estimates for all countries in the world corresponding to the 1950-2000 female birth cohorts (selected cohorts). Approximate size: $36 \mathrm{~KB}$. 


\section{References}

Alburez-Gutierrez, D. (2021a). Interactive web application for paper "Women's experience of child death: a global demographic perspective". Retrieved 2021-01-13, from https : / / osf.io/2pq3d/ doi: 10.17605/OSF.IO/2PQ3D

Alburez-Gutierrez, D. (2021b). Online Supplementary Materials for paper "Women's experience of child death: a global demographic perspective". Retrieved 2021-01-13, from https://osf.io/jdvhw/ doi: 10.17605/OSF.IO/JDVHW 